Original

\title{
Changes in the serum amino acids concentrations after first cycle as a factor predictive of tumor response to chemotherapy
}

\author{
M. Cobo-Dols ${ }^{1}$, E. Pérez-Miranda ${ }^{2}$, S. Gil-Calle ${ }^{1}$, I. Alés-Díaz ${ }^{1}$, E. Villar-Chamorro ${ }^{1}$, A. Montesa-Pino ${ }^{1}$, \\ J. Alcaide Garcia ${ }^{1}$, F. Carabante-Ocón ${ }^{1}$, M. Benavides-Orgaz ${ }^{1}$
}

\section{Summary}

- Objective: To detect variations of the serum amino acids (AA) profile in cancer patients undergoing chemotherapy to identify factors predicting the response to treatment.

- Material and methods: In 54 patients with lung, head and neck, and germ cell tumors, the circulating concentrations of 27 AA were prospectively measured at the basal line and following each chemotherapy cycle.

- Results: We observed changes in the majority of the AA following the first chemotherapy cycle in relation to the basal line. These changes were greater in those patients who responded to chemotherapy. Following the first chemotherapy cycle, the per cent increase with regard to the base line was significantly greater for $17 \mathrm{AA}$ in subjects responding to therapy when compared with those who did not respond.

- Conclusions: In patients responding to therapy, a rapid rise of the majority of the AA following the first cycle appears to be an early indicator of tumor response to cisplatin-containing chemotherapy.

Key words:

Amino acids. Chemotherapy. Tumor response

Oncología, 2005; 28 (7):321-328

Services of

${ }^{1}$ Oncología Médica

${ }^{2}$ Bioquímica y Análisis Clínicos

Hospital Regional Universitario Carlos Haya

Málaga 


\section{Resumen}

- Objetivo: Detectar variaciones en el perfil de AA séricos de pacientes neoplásicos sometidos a tratamiento quimioterápico, e intentar encontrar factores predictivos de respuesta tumoral.

- Material y métodos: En 54 pacientes con carcinoma de pulmón, cabeza y cuello y geminales sin alteraciones metabólicas ni otras patologías concomitantes se determinaron prospectivamente los niveles séricos basales de 27 aa diferentes y se analizan basalmente y tras cada ciclo de quimioterapia.

- Resultados: Observamos modificaciones en la mayoría de los AA medidos tras el primer ciclo de quimioterapia respecto a su nivel basal. Estas modificaciones fueron más ostensibles en sujetos con respuesta a la quimioterapia. La variable porcentaje de incremento de los AA (calculada teniendo en cuenta la diferencia del nivel de aa tras el primer ciclo de quimioterapia respecto al nivel basal) fue significativamente superior en 17 AA en sujetos respondedores frente a los no respondedores.

- Conclusiones: La elevación brusca de la mayoría de los aminoácidos tras el $1^{\circ}$ ciclo de quimioterapia, parece ser indicador predictivo precoz de respuesta tumoral.

Palabras clave: Aminoácidos. Qumioterapia. Respuesta tumoral

\section{Introduction}

Amino acids (AA) are simple monomeric subunits composed of a carboxyl group and an amino group bound to the same carbon atom ${ }^{1}$. The $20 \mathrm{AA}$ of the proteins are usually termed "standard" 2 . There are 5 principal AA groups: the apolar aliphatic "R" groups, the aromatic groups, the uncharged polar groups, the negatively charged groups, and the positively charged groups ${ }^{3}$. Ion exchange chromatography is the most used method to separate, identify and quantify each of the AA present in a mixture ${ }^{4}$.

The metabolic processes in the cancer patient are substantially different to normal subjects with peculiarities in the metabolism of the principal intermediates, not only with carbohydrates ${ }^{5,6}$ and fats ${ }^{7}$ but also with the proteins. The alterations of the AA metabolism and of the proteins in the organism of the patients with cancer are a consequence of metabolic dysfunction, such as accelerated gluconeogenesis and the increase in the synthesis of proteins in the li$\operatorname{ver}^{8}$. The degree of change in the pattern of the serum AA in cancer patients depends on variables such as: the specific type of tumor, the stage of the disease and its extent, and the presence or not of protein-caloric malnutrition ${ }^{9}$. The analysis of serum AA in the different studies conducted have been complicated by the heterogeneity of the neoplasias, as well as the difference in response to treatment employed $^{10}$.

The concentrations of some of the serum AA can be specific in relation to the type of tumor and according to the quality of influence on the metabolic status of the host ${ }^{11,12}$. The concentrations of these AA have been observed to return to their normal values after an efficacious therapy change again on disease relapse ${ }^{13}$. In murine models, specific patterns of AA profile have been observed in the serum of rats that have had a specific tumor-type implanted, and which normalizes when the tumor is extirpated ${ }^{14}$. In lung cancer, the increase in glutamic acid can be the result of an inefficient use of nitrogen since the tumor acts as a "nitrogen trap"15, competing with the host for nitrogenous components that are needed for its own protein synthesis; the glutamic acid being normalized when the tumor is extirpated ${ }^{16}$. Similar observations have been made in several studies in humans ${ }^{17-22}$.

Hence, change in the levels of AA can have importance in the clinical management of malignant neoplasias in that they can be used as markers of response to the oncologic treatment, as well as of early recurrence during follow-up ${ }^{23}$. In our study we analyzed variations of the profile of serum AA of 
patients with cancer undergoing chemotherapy with the intent of early identification of factors predictive of early tumor response to treatment.

\section{Materials and methods}

\section{Patient selection}

The study was prospective and included 54 patients with the diagnosis of cancer of the lung or head \& neck beyond surgery, and testicular tumors. The patients were treated in a single centre with chemotherapy based on cisplatin. The selection criteria were: age between 18-70 years; ECOG status $<2$; weight loss $<5 \%$; measurable disease; no previous chemotherapy; no concomitant endocrine-metabolic disorders or non-controlled hypertension or infections. Hepatic, renal cardiac and bone marrow function needed to be normal and the patient was not to be receiving food supplements; neither enteral nor parenteral.

\section{Therapeutic protocol}

In all the cases, cisplatin was employed at the same dose of $100 \mathrm{mg} / \mathrm{m}^{2}$ in cycles repeated every 21 days. The type of chemotherapy employed was cisplatin + etoposide in all the patients with lung cancer; cisplatin +5 -fluorouracil in all the patients with head \& neck cancer and the BEP (Bleomicine, Etoposide, Cisplatin) scheme in all the patients with germinal cell tumors. The chemotherapy was administered in hospital. Prior to the administration of each cycle of chemotherapy, a blood sample was taken for analysis (hemogram, glycemia, creatinine, electrolytes). We stopped the sample collection at the conclusion of the scheduled treatment, or treatment was suspended prematurely because of progression of the disease or of toxicity, or when there were factors that could alter the quality of the sample such as a loss of weight $>5 \%$, infections, or need for artificial nutrition. No other chemotherapy, immunotherapy or hormonal therapy was administered nor radiotherapy, or experimental medication while the patients were in the present study; neither did we use supplementary feeding (enteral nor parenteral). The response of the patients was evaluated every 3 cycles of chemotherapy, using clinical and radiographic techniques. The evaluation was according to the definitions of the WHO: Complete Response (CR): complete disappearance of the disease in two observation within an interval not less that 4 weeks; Partial Response (PR): decrease of $50 \%$ or more in tumor size and of the lesions measured in two observations within an interval of not less that 4 weeks and, as well, without the appearance of new lesions nor progression of any of the existing lesions.

\section{Laboratory measurements}

The measurements consisted of serum analysis of 27 different amino acids. Blood sampling was before the start of the chemotherapy and at $72 \mathrm{~h}$ after the administration of the chemotherapy cycle. The AA measured were: aspartic acid, taurine, theronine, serine, asparginine, glutamic acid, glutamine, proline, glycine, alanine, citrulline, aminobutyric acid, valine, cysteine, methionine, isoleucine, leucine, tyrosine, phenylalanine, tryptophan, ornithine, lysine, hystidine, arginine, hydroxyproline, 3-methyl hystidine, 1 methyl hystidine.

The AAs were measured with a Beckman System 6300/7300 Amino Acid Analyzer (Pickering Laboratories) according to the manufacturer's instructions and protocols. Samples for analysis were prepared from $1 \mathrm{ml}$ of blood collected into tubes containing heparin. An aliquot $(20 \mu \mathrm{L})$ whole blood was transferred to a $400 \mu \mathrm{L}$ centrifuge tube and 200 $\mu \mathrm{L}$ of a buffer solution ( $\mathrm{pH} 2.2$ containing a mixture of hydrochloric acid and citric acid), mixed thoroughly and frozen and stored at $-20^{\circ} \mathrm{C}$ for batched analysis to minimise methodological variation in measurement. Subsequently, the samples were thawed and centrifuged at $13,000 \mathrm{rpm}$ for $10 \mathrm{~min}$. To de-proteinise the sample, $200 \mu \mathrm{L}$ of the supernatant was taken with a micropipette, transferred to a 400 ( $\mathrm{L}$ centrifuge tube to which $20 \mu \mathrm{L}$ of sulphosalicylic acid was added and centrifuged at 13,000 rpm for 5 min. Supernatant $(5 \mu \mathrm{L})$ was mixed with $50 \%$ Li-A (Lithium citrate high performance AA analysis buffer) and passed through a $2 \mu \mathrm{L}$ filter

\section{Statistical analyses}

The comparisons of AA profile variation following the first chemotherapy cycle (dichotomized in- 
dependent qualitative variable and dependent quantitative variable with dependent samples) were with the Wilcoxon test. For the changes following the first cycle of treatment as a function of the tumor response, the dependent variable employed was defined as the "percentage of variation" $(\% \mathrm{~V})$ relative to the baseline using the following formula: $\% \mathrm{~V}=$ $\left(\mathrm{X}_{1}-\mathrm{X}_{\mathrm{b}}\right) / \mathrm{X}_{\mathrm{b}}$; (dichotomized qualitative independent variable and the quantitative dependent variable with independent samples) and comparisons were with the Mann-Whitney test.

Where:

$\mathrm{X}_{1}=\mathrm{AA}$ value following the first cycle

$\mathrm{X}_{\mathrm{b}}=\mathrm{AA}$ value at baseline

\section{Results}

The characteristics of the patients were as follows: the median age of the patients was 58 years (range 23-70). The gender distribution was 48 males (88\%) and 6 females (12\%). Tumor sites were 27 patients (50\%) with epidermoid carcinoma of the head \& neck, 24 patients (44.4\%) lung cancer 17 of whom (70\%) with histology of microcytic carcinoma and 7 patients (30\%) with non-microcytic carcinoma, and 3 patients $(5.6 \%)$ with malignant germcell testicular tumor.

A total of 254 cycles was administered and distributed as: 2 cycles to 1 patient $(1.9 \%) ; 3$ cycles to 3 patients $(5.5 \%)$; 4 cycles to 27 patients $(50 \%) ; 5$ cycles to 3 patients $(5.5 \%)$; 6 cycles to 20 patients $(37.1 \%)$. A total of 50 patients $(93 \%)$ received at least 4 cycles. There were 308 measurements made. Apart from measuring the levels of each of the $27 \mathrm{AA}$ at baseline ( 1 or 2 days prior to chemotherapy commencement) these same parameters were measured $72 \mathrm{~h}$ after the administration of each of the cisplatin cycles.

We established two groups according to the tumor response that occurred following the initiation of the chemotherapy: Group A: Patients with partial or complete response and Group B: No responding patients. In Figures 1 and 2 are representations of the
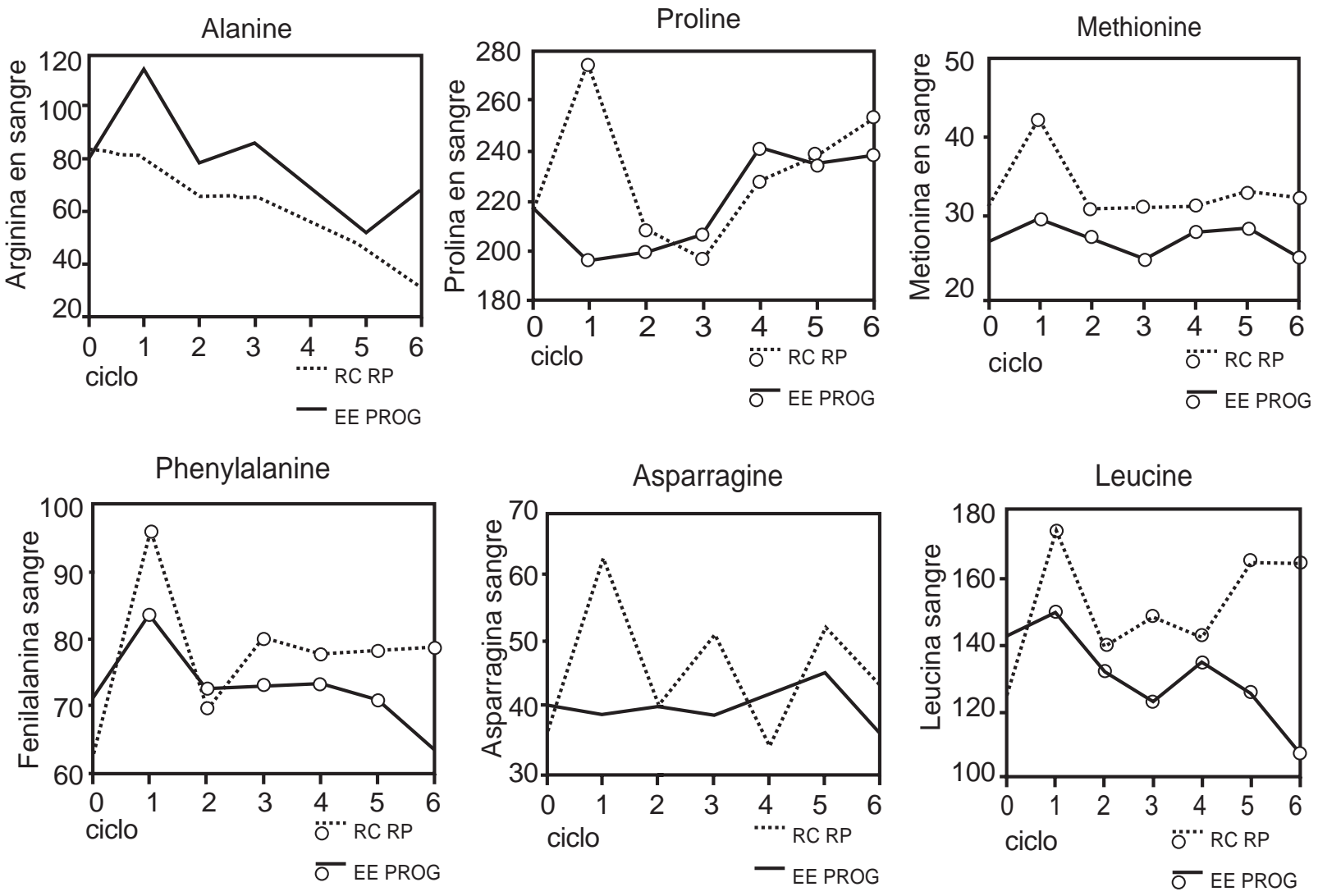

Figure 1. Variation in AA concentration following chemotherapy according to tumor response (I). 

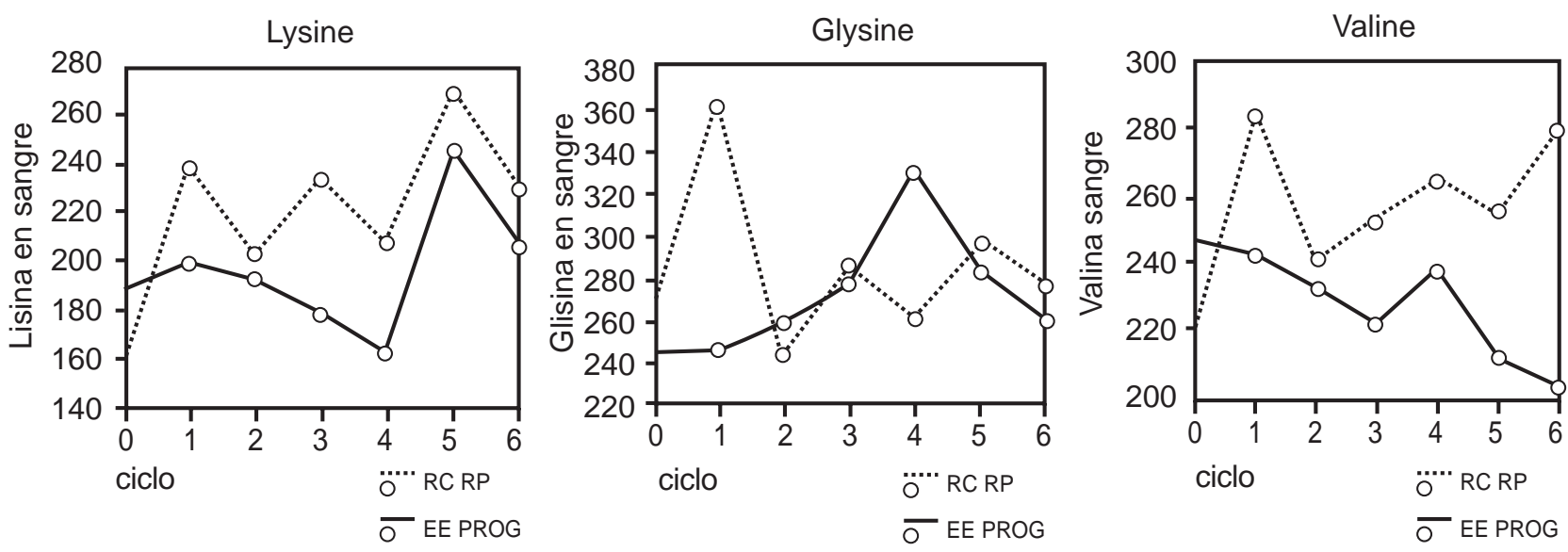

Histidine
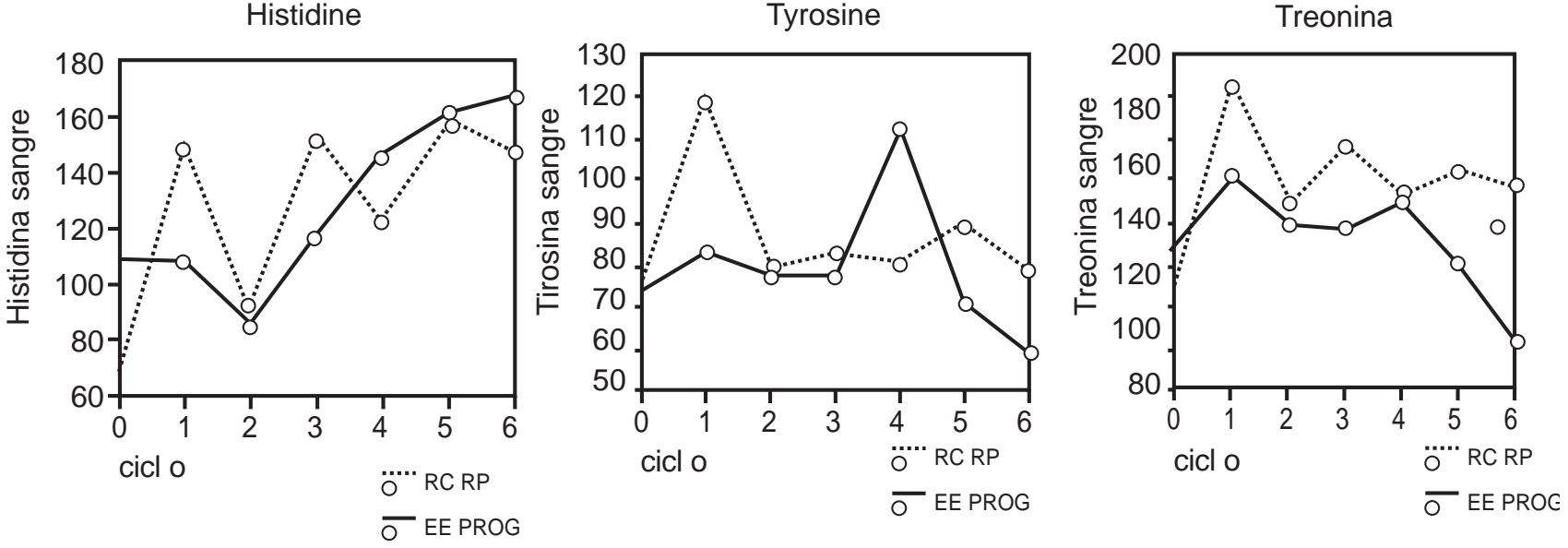

Figure 2. Variation in AA following chemotherapy and according to tumor response (II).

variations in the profile of most representatives AA, segregated with respect to tumor response to chemotherapy.

\section{Analyses of changes in the AA following the first cycle of chemotherapy}

The increase in the profile of serum AA evidenced in the overall group of the patients following the first cycle of chemotherapy was much more evident in the responders than in the non-responders. For example, in patients who were responders, the variation in the levels following the first cycle were statistically significant in 20 AA: alanine, arginine, asparagine, citrulline, phenylalanine, glycine, glutamine, hystidine, isoleucine, leucine, lysine, methionine, ornitine, proline, serine, taurine, tyrosine, threonine, tryptophan and valine. Ho- wever, in the patients who were non-responders, this difference was only significant in tryptophan, threonine, tyrosine, glutamine, phenylalanine and citrulline (Table I).

These data were obtained taking into account both sub-groups of patients separately. To compare these data of both sub-groups, the variable "percentage of increment" $(\% \Delta)$ was calculated for each amino acid. The increment in the level of the AA following the first cycle of chemotherapy with respect to the baseline concentrations (measured as percentage increment) was significantly greater in the patients who responded to the therapy than those who did not in relation to 17 of the amino acids: alanine, arginine, asparginine, citrulline, phenylalanine, glycine, hystidine, isoleucine, leucine, lysine, methionine, ornitine, proline, serine, tyrosine, theronine and valine (Table II). 
TABLE I

AA after first chemotherapy cycle compared to baseline

\begin{tabular}{|c|c|c|c|}
\hline Amino Acid & $\begin{array}{c}\text { Overall } \\
\text { patient group } \\
P\end{array}$ & $\begin{array}{c}\text { Responders } \\
P\end{array}$ & $\begin{array}{c}\text { Non- } \\
\text { Responders } \\
P\end{array}$ \\
\hline 3-metylhistidine & NS & NS & NS \\
\hline Aminobutyrate & 0.04 & NS & NS \\
\hline Aspartic acid & NS & NS & NS \\
\hline Glutamic acid & NS & NS & NS \\
\hline Alanine & $<0.001$ & $<0.001$ & NS \\
\hline Arginine & 0.004 & $<0.001$ & NS \\
\hline Asparagine & 0.002 & $<0.001$ & NS \\
\hline Cysteine & NS & NS & NS \\
\hline Citrulline & NS & 0.01 & 0.02 \\
\hline Phenylalanine & $<0.001$ & $<0.001$ & 0.004 \\
\hline Glycine & 0.002 & 0.001 & NS \\
\hline Glutamine & $<0.001$ & $<0.001$ & 0.03 \\
\hline Hystidine & $<0.001$ & $<0.001$ & NS \\
\hline Isoleucine & NS & 0.007 & NS \\
\hline Leucine & $<0.001$ & $<0.001$ & NS \\
\hline Lysine & $<0.001$ & $<0.001$ & NS \\
\hline Methionine & $<0.001$ & $<0.001$ & NS \\
\hline Hydroxyproline & NS & NS & NS \\
\hline Ornitine & 0.009 & $<0.001$ & NS \\
\hline Proline & 0.017 & 0.002 & NS \\
\hline Serine & $<0.001$ & $<0.001$ & NS \\
\hline Taurine & NS & 0.04 & NS \\
\hline Tyrosine & $<0.001$ & $<0.001$ & 0.02 \\
\hline Threonine & $<0.001$ & $<0.001$ & 0.0027 \\
\hline Tryptophan & $<0.001$ & 0.001 & 0.012 \\
\hline Valine & 0.01 & $<0.001$ & NS \\
\hline
\end{tabular}

\section{Discussion}

Although the specificity of changes in AA levels in relation to tumor etiology is still not clearly demonstrated, it is evident that these increases return to their normal values following an efficacious therapy, and increase again with disease relapse ${ }^{13}$. Experimentally, there have been specific patterns demonstrated in the serum AA of rats in which specific tumors had been experimentally induced, and which return to normal when the tumor is extirpated ${ }^{14}$. For this reason that, in our study, we analyzed the serum AA at baseline and after each successive cycle of chemotherapy so as to generate a profile of the changes that may be useful in proposing factors that could be predictive of recurrence.

However, clinical studies following this path are rare. The study by Elling et $\mathrm{al}^{22}$, with a 2 year follow-up of patients with breast cancer, correlated the changes in the AA profile with the disease recurrence. Studies conducted after the surgical extirpation of tumors have demonstrated a normalization of AA that, previously, had been altered ${ }^{24}$. Similar post-surgical decreases in AA had been detected in other studies $^{25}$ and, although the patho-physiological mechanisms underlying these findings have not been delineated, the probable explanation may be due to the cessation of the tumor influence on the protein metabolism of the host.

We have not encountered, in the literature, any

TABLE II

Comparisons of change $(\% \Delta)$ in $\mathrm{AA}$ following the first chemotherapy cycle

\begin{tabular}{|c|c|c|c|}
\hline Amino Acid & Responders Versus Non-Responders & Amino Acid & Responders Versus Non-Responders \\
\hline 3-methyl-histidine & NS & Isoleucine & 0.014 \\
\hline Aminobutyric acid & NS & Leucine & 0.002 \\
\hline Aspartic acid & NS & Lysine & 0.005 \\
\hline Glutamic acid & NS & Methionine & 0.002 \\
\hline Alanine & 0.007 & Hydroxyproline & NS \\
\hline Arginine & 0.006 & Proline & 0.001 \\
\hline Asparagine & $<0.001$ & Serine & 0.02 \\
\hline Cysteine & NS & Taurine & NS \\
\hline Citrulline & 0.002 & Tyrosine & 0.02 \\
\hline Phenylalanine & 0.001 & Threonine & 0.006 \\
\hline Glycine & 0.01 & Tryptophan & NS \\
\hline Glutamine & NS & Valine & 0.002 \\
\hline Hystidine & 0.001 & Ornitine & 0.001 \\
\hline
\end{tabular}


study that had analyzed the changes in the AA profile with the use of chemotherapy, and correlation of the findings with tumor response to the chemotherapy. We began with the hypothesis that the responder patients have significant changes in the AA profile relative to the non-responders. In the analysis of each one of the AA following each cycle of chemotherapy we observed clear alterations in the AA profile of the responders with respect to the cycles administered; statistically significant differences in 21 $\mathrm{AA}$ in the responders while, in the non-responders, the changes were significant in only $3 \mathrm{AA}$.

A very notable finding in our study is that when we analyze the curves in AA profile changes during the course of chemotherapy, we observe that the most significant changes are produced following the first cycle of chemotherapy, and that this increase was much more evident in the responder than the non-responder patients. In the responders, the changes in the AA levels following the first cycle of chemotherapy relative to baseline were significant in 20 AA while that in the non-responders these differences were only significant in 6 AA. In comparing the responders with the non-responders, statistically significant differences between the two sub-groups were observed in a total of 17 AA.

Based on the above observations, it would appear that a decrease in the size of the tumor at least in the types of cancer studied and with the use of chemotherapy based on cisplatin, clear changes in the AA profile are induced, especially following the first cycle. However, our study was not able to demonstrate whether the reduction or disappearance of the tumor results in a normalization of the AA that were altered previously. The progressive destruction of tumor cells with the cytostatic agent produces different biochemical alterations that set in motion a series of mechanisms to re-utilize the products of tumor destruction. This evidence for this is that these changes and variations in the serum amino acid profile are noted in patients in whom the chemotherapy has been effective and, as such, a greater availability of AA results as a consequence of the destruction of cellular proteins of the tumor and the decrease in their synthesis.

Hence, a rapid increase in the levels of circulating AA following the first cycle of a chemotherapy scheme can serve as an early predictor of tumor response. Further studies with a greater number of pa- tients including other histological types of tumors and with other schemes of treatment are needed to confirm this hypothesis. Serial measurements of serum AA in cancer patients undergoing chemotherapy could provide an early prediction of the probability off success of the treatment and, conversely, to modify the therapeutic approach if indices of probable of failure of the treatment are detected.

\section{Correspondence:}

Manuel Cobo-Dols, MD

Sección de Oncología Médica

Pabellón A, $3^{\circ}$ planta Derecha

Secretaría de Oncología Médica

Hospital Regional Universitario Carlos Haya

Avda Carlos Haya, s/n

E-29010 Málaga

E-mail: manuelcobodols@yahoo.es

E-mail (alternative):mangel.cobo.sspa@juntadeandalucia.es

\section{References}

1. Jope EM . The emergence of man: information from protein systems. Philosophical Transactions of the Royal Society of London - Series B: Biological Sciences 1981;292 (1057):121-131.

2. Scriver CR, Lamm P, Clow CL. Plasma amino acids: screening, quantitation, and interpretation. Am J Clin Nutr 1971;24(7):876-890.

3. Frommel $\mathrm{C}$. The apolar surface area of amino acids and its empirical correlation with hydrophobic free energy. J Theor Biol 1984;111(2):247-260.

4. Lochmuller CH, Souter RW. Chromatographic resolution of enantiomers selective review. J Chromatography 1975; 113:283-302.

5. Morris DR, Fillingame RH. Regulation of amino acid decarboxylation. Ann Rev Biochem 1974;43:303-325.

6. Fleschmann W. The metabolism of damaged cells and tissues. Cold Spring Harbor Symposia on Cuantitative Biology 1989;7: 290-300.

7. Lanza-Jacoby S, Lansey S, Miller EE, Clearly MP. Sequential changes in the activities of lipoptotein lipase and lipogenic enzymes during tumor growth in rats. Cancer Res 1984;44: 5062-5067.

8. Lundholm K, Bylund AC, Schersten T. Skeletal mucle metabolism in patients with malignant tumor. Eur J Cancer 1976;12: 465-473.

9. Holt LE, Snyderman SE, Norton PM, Roiman E, Finch J. 
The plasma aminogram in kwashiorkor. Lancet 1963;2: 1343-1348.

10. Clark EF, Lewis AM, Waterhose C. Periferal amino acid levels in patients with cancer. Cancer 1978;42:2909-2913.

11. Kern KA, Norton JA. Cancer cachexia. JPEN 1988;12: 286-298.

12. Russell DM, Shike M, Anderson GH. Amino acid metabolism in small cell lung cancer. J Parenter Enteral Nutr 1981;6:592.

13. Elling D, Bader K, Schicke B. Free serum amino acids in patientts with tumors of different sites - tumor induced imbalances. Zentralbl Gynakol 1987;109:1023-1032.

14. Kuzer M, Janizewski J, Meguid MM. Amino acid profiles in tumor-bearing and pair-fed nontumor-bearing malnourished rats. Cancer 1988;62:30-

15. Landel AM, Hammond WG, Meguid MM. Aspects of amino acid and protein metabolism in cancer bearing states. Cancer 1985;55:230-237.

16. Landel AM, Lo CC, Meguid MM, Rivera D. Effect of metyl-colanthrene- induced sarcoma and its removal on rats and intracelular free amino acid content. Surg Res Commun 1987;1:273-287.

17. Cascino A, Cangiano C, Ceci F, Franchi F, Menichetti ET, Muscaritoli M. Plasma aminoacid in human cancer: the individual role of tumor, malnutrition and glucose tolerance. Clin Nutr 1988;7:213-218.
18. Meguid MM, Muscaritoli, Beverly Jl, Yang ZJ, Cangiano C, Rosi Fanelli F. The early cancer anorexia paradigm: changes in plasma free tryptophan and feeding indexes. J Parent Enteral Nutr 1992;16:56S-59S.

19. Cascino A, Cangiano C, Ceci F, Franchi F, Mineo T, Mulieri M. Increased plasma free tryptofan levels in human cancer: a tumor releated effect? Anticancer Res 1991;11: 1313-1316.

20. Cascino A, Muscaritoli M, Cangiano C, Conversano L. Plasma aminoacid imbalance in patients with lung and breast cancer. Anticancer Res 1995;15:507-510.

21. Elling, Bader K, Schicke B. Use of free serum amino acids in therapy monitoring of patients with treated vulvar cancer. Zentralbl Gynakol 1987;109:654-662.

22. Elling D, Bader K. Therapeutic monitoring of breast cancer patients by means of free serum amino acids. Arch Geschwulstforsch 1986;56:23-33.

23. Zhang PC, Pang CP. Plasma aminoacid patterns in cancer. Clin Chem 1992;38:1198-1199.

24. Naini AB, Dickerson JWT, Brown MM. Preoperative and postoperative levels of plasma protein and amino acid in esophageal and lung cancer patients. Cancer 1988;62:355360.

25. Dale G, Young F, Latner AL, Goode A, Tweedle D, Johnton IDA. The efect of surgical operation on venous plasma free amino acids. Surgery 1977;81:295-301. 